EDUARDO

SERRANO GONZÁLEZ

FRANCISCO DE LA

TORRE OLIVER
Universitat Politècnica de València eduardosego91@gmail.com Universitat Politècnica de València pacodltorre@gmail.com

\title{
Registrar la memoria desechada. Rastreadores de escombros.
}


RECORDERS AT THE DISCARDED MEMORY. TRACKERS OF DEBRIS.

\section{ABSTRACT}

The present work analyzes how the contemporary consumer society transforms the city into a producer of abandoned memory waste, and how these objects star in the photographic archive on social networks of the so-called waste trackers. A phenomenon that would be questioning the construction of collective memory from new perspectives. After this observation, we propose to face the analysis of the discarded object as a metaphor for memory by means of a possible analogy between these urban trackers and the Angel of Walter Benjamin's story. In the same way, we will link this phenomenon to the paradigm shift of what can be photographed, largely motivated by the popularization of the integrated camera on mobile devices and image sharing applications. Finally, based on these keys, we will analyze a series of accounts on social networks where their authors develop alternative artistic discourses.

\section{Keywords}

Photography; abandonment; object; memory; archive; scrap.

\section{RESUMEN}

El presente trabajo analiza cómo la sociedad de consumo contemporánea transforma la ciudad en productora de desechos de memoria abandonados, y cómo estos objetos protagonizan el archivo fotográfico en redes sociales de los denominados rastreadores de desechos. Un fenómeno que estaría cuestionando la construcción de la memoria colectiva desde nuevas perspectivas. Tras esta observación, planteamos afrontar el análisis del objeto desechado como metáfora de la memoria mediante una posible analogía entre estos rastreadores urbanos y el Ángel de la historia de Walter Benjamin. Del mismo modo, vincularemos este fenómeno al cambio de paradigma de lo fotografiable, motivado en gran medida por la popularización de la cámara integrada en dispositivos móviles y las aplicaciones para compartir imágenes. Finalmente, en base a estas claves analizaremos una serie de cuentas en redes sociales donde sus autores desarrollan discursos artísticos alternativos.

\section{Palabras clave}

Fotografía; abandono; objeto; memoria; archivo; desecho. 


\section{INTRODUCCIÓN}

La continua trasformación de la sociedad, el aumento exponencial del consumo y la superpoblación, convierten a las ciudades contemporáneas en grandes productoras de basura de diferente naturaleza. La orgánica va directa a los vertederos, también existen modernos contenedores de reciclaje de diferentes usos, pero cada vez con mayor frecuencia aparecen objetos cotidianos, enseres o mobiliario de la vida moderna abandonados en cualquier lugar. La observación de este fenómeno ha motivado el punto de partida del presente trabajo, tanto desde la propia producción artística como mediante la investigación teórica, planteando las claves conceptuales que vincularían el objeto y la memoria, desde la práctica pictórica y el medio fotográfico.

Este creciente interés por el objeto desechado nos condujo al hallazgo de una serie de cuentas en las redes sociales de compartición de imágenes fotográficas, en su gran mayoría anónimas, que registran de manera metódica, objetiva y organizada, objetos desechados encontrados en la vía pública. Este hecho accidental motivó nuestro interés por profundizar en la búsqueda de nuevas cuentas dedicadas al mismo objetivo. A través de palabras clave y el empleo de hagstag como \#furniture \#abandoned \#streetfurniture \#abandonedfurniture \#lonelychair \#lonelyfurniture \#abandonedchair, etc. se identificaron diferentes cuentas dedicadas a registrar, en base a parámetros definidos, todo tipo de objetos domésticos desechados, principalmente mobiliario. Con la elaboración de este repositorio comprobamos que, a pesar de compartir ciertas claves estéticas y conceptuales, se trataba de manifestaciones artísticas aisladas en diferentes contextos sin ningún nexo aparente entre ellas, más allá de sus etiquetas.

A este objeto de estudio lo hemos denominado Rastreadores de Desechos. Una mirada compartida, siempre atenta a las manifestaciones de los restos de una sociedad en tránsito, aquellas trazas que quedan al margen.

Por ello, tras realizar esta particular catalogación, nos planteamos definir las claves conceptuales de estos registradores de desechos, siguiendo sus antecedentes, para así poder definirla como una corriente de expresión artística contemporánea.

Con tal de responder a nuestra hipótesis nos serviremos de una metodología de investigación, a partir del estudio analítico de referencias teóricas pertinentes, para responder a diferentes objetivos.

En primer lugar, analizaremos las claves conceptuales que definen la fotografía en estos registros. Partimos de la lectura de El Ángel de la historia de Walter Benjamin, vinculando la mirada alegórica al pasado en el cuadro de Paul Klee con la de los rastreadores de desechos. Del mismo modo, realizamos una lectura del objeto desechado en su discurso, de tal forma que podamos comprender la importancia de la vinculación que establecen con sus capacidades metafóricas. Por último, en este análisis conceptual realizamos una lectura del posicionamiento de esta corriente frente a las problemáticas en torno a la mirada al pasado.

En el siguiente apartado, abordaremos algunas de las claves del cambio de paradigma de lo fotografiable, partiendo de la introducción de la cámara fotográfica en los dispositivos móviles. Posteriormente, revisaremos los fundamentos de la fotografía de archivo como referente del trabajo de los registradores en las redes sociales. 
Una vez planteada nuestra teoría, analizaremos una serie de creadores que, al vincular arte y archivo, han elaborado en su obra planteamientos conceptuales que se reconocen en los repositorios virtuales analizados. Realizado este estudio, procederemos a clasificar en base a sus claves conceptuales el repositorio de cuentas de rastreadores de desechos elaborado para nuestro trabajo en la red social Instagram.

Por lo tanto, en la presente investigación ofrecemos una lectura, desde el ensayo y las prácticas artísticas de archivo, que nos permita entender el discurso de un grupo de fotógrafos denominados rastreadores de desechos. Una corriente que, con su práctica, provoca un cuestionamiento de las redes sociales y las aplicaciones móviles actuales, aplicando conceptos heredados del siglo XX. Estos activistas encuentran en internet una ventana para trasmitir discursos críticos a cerca de nuestro pasado reciente a través de nuestros propios despojos. Los restos dejados en el camino por una sociedad en tránsito, que llevada por la inercia del progreso se dirige irremediablemente hacia un futuro incierto.

\section{LA MEMORIA Y EL ESCOMBRO}

\subsection{Llevados por el huracán}

Con el objetivo de contextualizar el campo de actuación de nuestro estudio, planteamos como punto de partida la lectura realizada por Walter Benjamín de la acuarela conocida como Angelus Novus realizada por Paul Klee en 1920, (el Ángel de la Historia para Benjamín). Esta reflexión se encuentra recogida en el IX apartado de las Tesis sobre el concepto de historia en 1940:

Hay un cuadro de Klee que se titula Angelus Novus. En él se representa a un ángel que parece como si estuviese a punto de alejarse de algo en lo que fija su mirada. Los ojos como platos, la boca, muy abierta, las alas, totalmente extendidas. Este debe de ser el aspecto del ángel de la historia. Ha vuelto el rostro hacia el pasado. Allí donde nosotros vemos un encadenamiento de hechos, él ve una única catástrofe que acumula incesantemente una ruina tras otra, arrojándolas a sus pies. Bien quisiera él detenerse, despertar a los muertos y recomponer tanta destrucción. Pero, desde el Paraíso, sopla una tempestad que se ha enredado en sus alas y que es tan fuerte que el ángel ya no puede cerrarlas. Esta tempestad lo empuja hacia el futuro, al que él da la espalda, mientras que los montones de ruinas van creciendo ante él hasta llegar al cielo. Esta tempestad es lo que nosotros llamamos «progreso». (Benjamin, 2005, p. 44)

En esta interpretación, Benjamin aprecia el rostro del Ángel de la Historia dirigiendo su mirada al pasado, de este modo estaría vislumbrando una catástrofe que en su trascurso acumula las ruinas sobre sus pies. Su voluntad es detenerse, recomponer el desastre, pero la "tempestad" lo empuja en un movimiento continuo hacía el futuro, al cual da la espalda. Este huracán que impide el movimiento del Ángel es el progreso. En tiempos posmodernos, esta mirada del Ángel a la ruina, al dolor generado por el progreso en los tiempos pasados, "se produce sin compasión, sin un ápice de mala conciencia, ya que de ahí extrae su bienestar" (Fernández, 2018, p. 360).

En este sentido, entendemos que, al dirigir su atención al pasado reciente, la lectura de los activistas objeto de nuestro estudio no respondería a una mirada posmoderna puesto que, al reconstruir o metaforizar ese pasado, no emplea una simulación edulcorada, precocinada o exagerada. Por contra, podemos entender que se trata de un posicionamiento próximo al carácter 
moderno, mediante el hecho de dotar de un sentido artístico o metafórico al desperdicio, a la basura. Aquello que "la moral tradicional desprecia u oculta" (Fernández, 2018, p. 363).

Esta alegoría de Benjamin, nos permitiría vincular la mirada del Ángel de la Historia con los artistas que hemos denominado "rastreadores de desechos". La mirada del Angelus Novus es el objetivo de la cámara del registrador, donde los demás vemos la ruina, a través de la lente fotográfica ellos descubren los desechos acumulados por el progreso. El Ángel se presenta con una voluntad arqueológica, pero ahistórica, representaría la realidad a escala 1:1. Por tanto, es en esta mirada al pasado, hacia la ruina producida por el huracán del progreso, donde encontramos la perspectiva artística mediante la cual se generan los trabajos de registro fotográfico que analizamos.

Observamos que en la Tesis IX, Benjamin expone la idea de ruina, como aquella que se amontona. Es de esta idea de ruina, de donde extraemos el concepto de "objeto desechado", que registrará el rastreador con su cámara. Para definir estos términos seguiremos el planteamiento de Fernández: "Ruina y escombro son, pues, conceptos y realidades diametralmente opuestas. Toda Ruina se aposenta en su correspondiente escombro, problemático y Real" (2018, p. 364). Por lo tanto, los rastreadores, con la mirada benjaminiana del Ángel de la Historia, buscan entre la ruina, el escombro, un fragmento de realidad en forma de desecho de la sociedad moderna. Este fragmento desechado se convierte, de tal modo, en metáfora con capacidad de formar parte de una obra artística, en una práctica que el propio Fernández llamará docuficción.

El trabajo de la docuficción que se analiza en Teoría general de la basura, consiste en la emersión de ese escombro, escarbar, rastrear entre el mismo para sacarlo a la luz. De tal forma, "toda ruina dejará inaccesible el escombro que oculta" (Fernández, 2018, p. 365), siendo por tanto labor de los rastreadores devolver a la luz los desechos de entre la ruina, y dar cuenta de los mismos mediante el registro fotográfico.

\section{2}

Montañas de deshechos

Por lo tanto, y con tal de clarificar la idea de objeto a la cual nos referimos, acudimos a La Real Academia de la Lengua Española que define objeto como: "todo lo que puede ser materia de conocimiento o sensibilidad de parte del sujeto, incluso este mismo". Podemos entenderlo como un resultado de la acción del hombre en el mundo, su relación, aquello que puede ser deseado, utilizado, adquirido y vulnerable de cualquier tipo de manipulación humana.

En esta línea, cabe revisar con Juan Antonio Ramírez, la definición que hace la RAE de la palabra cosa: “Objeto inanimado, por oposición a ser viviente". Al establecer esta relación entre cosa y objeto frente a sujeto, podría interpretarse que el arte siempre se habría ocupado de los objetos, de repensarlos y representarlos, ya fueran profanos o sacros. Más allá de la mera interpretación formal, también han tenido un carácter alegórico o metafórico, que elevaba a transcendental la condición de simple "objeto entre los objetos terrenales" (Ramírez, 2009, p. 103).

Así, el objeto se muestra de frente como una realidad que afecta a nuestro sentido. Tratándose de algo que es visible y a la vez palpable, alejado del sujeto. "El objeto es una realidad que se manipula, que se mide y se pesa, que se puede asir, poseer o abarcar con la mirada" (Guigon, 1997, p. 9). Pero se da la circunstancia que este carácter tangible del objeto, del mismo modo que expone Platón en El mito de la caverna, al intentar ver su esencia -o descubrir la metáfora 
que encierra- lo tangible del objeto desparece, y crea un conflicto que estaría más relacionado con la memoria que con los sentidos.

Por tanto, podríamos calificar al objeto desechado, como objeto de memoria y sombra de la historia, lo que no cabe en su relato, su otro latente (Hernández, 2012, p. 29). Un hecho que nos permitiría considerar que estas prácticas artísticas transforman el objeto desechado en un generador de discursos de pasado, pero también de futuro, actuando a razón del papel de artista historiador definido por Walter Benjamín. De este modo, el pasado no se entiende como un elemento sólido y cerrado, si no como algo abierto a relecturas y que, en su extensión afecta al presente, convirtiéndose, de este modo, en el tiempo activo de la arqueología como simulacro.

En consecuencia, el registro fotográfico que nos ocupa, al tomar como referente el objeto abandonado, se enmarcaría en esta línea de pensamiento. Insertada en un trabajo de búsqueda entre la ruina, de un escombro materializado en el objeto de registro que se recontextualiza en el presente, otorgando al referente fotográfico el valor de metáfora. Por tanto, observamos que, dentro de este marco estético contemporáneo, no se definiría al objeto por su sublimación, ni por su aura, sino que se destacaría su tránsito, "las trazas, que a través de espacios nos llevan a él y se incorporan a él” (Fernández, 2018, p. 373).

Este intento de recuperación, y de puesta en valor de ese trayecto de regreso del pasado al presente, se encontraría asociado al concepto de historia de Walter Benjamín que nos interroga acerca de la posibilidad de aprovechamiento de ese camino de vuelta hacia el pasado como una ruta de limpieza de los daños cometidos por "los futuros que sí se hicieron presente" (Bauman, 2018, p.16).

De tal forma que, dentro de las claves del objeto desechado, debemos señalar el interés por el objeto cotidiano por parte de nuestros rastreadores. No resulta baladí este hecho, puesto que dota al objeto de unas cualidades metafóricas concretas. Como señala Baudrillard, estos objetos son "los objetos de una pasión, la de la propiedad privada", para añadir que son: "un recinto mental en el cual yo reino, una cosa de la cual yo soy el sentido, una propiedad, una pasión" (1969, p. 103). Por este motivo, el objeto cotidiano, más allá de su materialidad o su referencialidad del pasado, es símbolo de una pasión, metáfora de una afección pasada asociada a su anterior propietario.

Por último, debemos detenernos en algunas de las claves conceptuales asociadas al mobiliario abandonado, uno de los principales referentes de los rastreadores de desechos en base a su presencia en los repositorios. El mobiliario sería entendido en estos registros como discretos acompañantes de nuestra cotidianidad y "testigos mudos de nuestro existir" (Reyes, 1989, p. 856). Tanto es así, que almacenaríamos en nuestra mente un conglomerado de objetos imaginarios basados en nuestra experiencia vital. Enseres que, en algún momento, han formado parte de nuestra vida y, pese a encontrarse relegados en nuestra memoria, pueden ser evocados al enfrentarnos como espectadores a la representación fotográfica del mobiliario desechado.

La evocación que encontramos en estos archivos sería comparable a la referida por el psicoanalista Cristopher Bollas (1987), quien describe la visita a una tienda de muebles como el contacto con un almacén de elementos cargados de significados. Puesto que, al reconocer en ellos parte de nuestra memoria, se rememoran y generan diversos estados psicológicos en relación con el almacén de datos de experiencia vital que contienen. 


\subsection{El camino de regreso}

Retomando la interpretación del Angelus Novus, podemos observar una lectura de la historia dotada de un eco trágico al encontrarse enfrentada a la idea de progreso ascendente. La escena nos sugiere, por tanto, la dificultad de pensar el tiempo de tal modo que pudiera existir la posibilidad de vislumbrar alguna suerte de futuro. El Ángel se dirige irremediablemente empujado por el huracán, hacía la evolución, que sucede a su espalda, mientras su mirada está condenada a ser testigo impasible de lo que ve.

En esta dirección cabe cuestionar el sentido de la memoria, y la forma de mirar al pasado, que configura la visión desde la que leer los trabajos fotográficos de los registradores. En respuesta a ello observamos, como apunta Zigmund Bauman (2018) en relación a Svetlana Boym, que el entendimiento contemporáneo del pasado iría ligado a un sentimiento de nostalgia. El cuál, tras haber sido tratado como enfermedad en s. XVII, llega a la sociedad contemporánea en forma de patología incurable (p. 12-13). Esta afección nostálgica se debería a una acción compensatoria, un sentimiento mediante el cual paliar el vacío y la fragmentación social generado por la ausencia de futuros. La nostalgia reaparece entonces "como un mecanismo de defensa en un tiempo de ritmos de vida acelerados y de turbulencia histórica" (Boym, 2001, p. 109).

Esta situación de realidad nostálgica a la que apunta Boym, nos sitúa como herederos de un contexto anterior. Un tiempo previo de exaltación exacerbada del progreso que, de manera tan lenta como imparable, se extiende a través de la carrera de la historia. De tal manera que llega a la actual "epidemia global de nostalgia" (Bauman, 2018, p. 13).

Es por ello por lo que el diagnóstico de Boym apuntaría hacia una sociedad aquejada de un anhelo de memoria colectiva, las formas de recordar convencionales no responden a las exigencias de nuestras sociedades. De modo que, el objetivo de los discursos artísticos de los rastreadores de desechos estaría orientado a crear relatos colectivos sobre un pasado reciente, dando así respuesta a las carencias sociales apuntadas. Pero, desde una perspectiva alejada de la evocación nostálgica y centrada en la construcción de nuevos espacios de recuperación del pasado. De tal forma que estas acciones comporten una introducción de discontinuidad sobre el presente, adquiriendo la capacidad de transformarlo y abrir la posibilidad de crear algo nuevo.

En línea con lo expuesto anteriormente, debemos ubicarnos en el contexto de una nueva etapa que nos permite entender los discursos de los rastreadores del desecho dentro del cambio de paradigma en relación con lo bello. Este concepto se asoció a la idea de tiempo vinculada al progreso en diversas fases del capitalismo, por lo que la belleza se encontraba asociada al cambio, a un utópico futuro. Una concepción que se trastocará en la posmodernidad, sustituyendo la idea de progreso por una mirada dirigida al pasado. Un concepto de belleza intrínsecamente relacionado con la idea de nostalgia de Boym, ante la imposibilidad de realización de ese pasado.

Por todo ello, retomamos la siguiente cuestión, "¿Acaso no podría aprovecharse el camino de vuelta, hacia el pasado, para convertirlo en una ruta de limpieza de todos esos daños cometidos por los futuros que si se hicieron presentes en algún momento?" (Bauman, 2018, p.16). Encontramos como los rastreadores del desecho escarban en las ruinas del progreso, rescatando de entre sus escombros los objetos abandonados, para traerlos a nuestro presente. Y no solamente desde un proceso de evocación melancólica, si no en un acto consciente de aludir -mediante un objeto testigo de nuestro existir- a nuestra memoria individual. Pero también, 
haciendo del objeto registrado una metáfora de un sentir colectivo, generando la ventana de nuevas reinterpretaciones del pasado que configurarían nuestro presente.

\section{FOTOGRAFÍA DIGITAL Y CLAVES DEL CAMBIO DE PARADIGMA}

En relación a nuestro objeto de estudio, y como clave en la generación de discursos, interviene un segundo factor: la fotografía y su comunión con lo digital. Esta transformación del paradigma de "lo fotografiable" se potenciaría exponencialmente a partir de la incorporación de cámaras digitales en los dispositivos móviles, la aparición de las redes sociales y la posibilidad de compartir imágenes de modo global.

Será mediante este cambio de paradigma como hemos pasado de la captura meditada y valorada, a la captura compulsiva. Un hecho que derivaría en un cambio del objeto fotográfico, ya que "en la era digital, lo fotografiable ya no significa algo concreto, en esta radical mundialización con la que la práctica fotográfica se ve de modo irreversible dominada por lo ordinario" (Martín Prada, 2018, p. 13-15). El acto de generar y consumir imágenes sería un fenómeno inherente a la cámara fotográfica, provocando en el usuario la necesidad de fotografiarlo todo dentro de la lógica interna del capitalismo.

Los avances tecnológicos y los nuevos medios habrían incidido en acrecentar la necesidad de reabastecimiento de imágenes, desatando una lujuria que nunca se puede satisfacer, "primero, porque las posibilidades de la fotografía son infinitas, y segundo, porque el proyecto termina por devorarse a sí mismo" (Sontag, 2005, p. 250). Por lo cual, el dispositivo móvil habría dejado de ser un soporte tecnológico, para convertirse en un instrumento que -a modo de gadgetprolongaría el cuerpo humano, transformando el registro en un nuevo hábito cultural.

Este hecho nos lleva a considerar, siguiendo el pensamiento de Okwui Enwezor, que "la cámara es literalmente una máquina de archivo, toda fotografía, todo film es a priori un objeto de archivo" (2008, p. 11). Un nuevo paradigma que se uniría al sistema web y a las aplicaciones para la difusión de imágenes en redes sociales.

Por tanto, centrándonos en la actividad artística en las redes sociales, surge un cuestionamiento en torno a la idea de fotógrafo amateur. Puesto que la unión en las plataformas de redes sociales de un usuario como creador y consumidor al mismo tiempo, afecta a la idea tradicional de amateur. Una idea planteada por Ronald Barthes del siguiente modo: "El amateur, el aficionado, no se define forzosamente por un saber menor, por una técnica imperfecta. Sino más bien por lo siguiente: es el que no muestra, el que no se hace oír" (1986, p. 284). De esta manera, la evolución de dichas redes permite al usuario ser consumidor al tiempo que generador de contenidos en su papel de profesional amateurism y amateur professionalism (Prada, 2018, p. 37).

Por ello, en relación a este cambio de lo fotografiable, observamos que las manifestaciones artísticas objeto de nuestro estudio responderían a la idea de registro fotográfico de archivo. Un arte de inventario que, en la segunda década del siglo XX, la Neue Sachlinchkeit (Nueva Objetividad) alemana reconocería en el concepto de distanciamiento u objetividad entre el fotógrafo y la realidad.

En relación con los rastreadores, podríamos señalar como antecedente de los parámetros de la 
Nueva Objetividad al fotógrafo francés Eugène Adget y sus primeras fotografías datadas entre 1896 y 1898 . En sus trabajos destaca la voluntad de configurar una catalogación, manteniendo al autor en un segundo plano. Como señala Rosalind Krauss, para Adget "la autoría es un término irrelevante" (2002, p. 52). En su caso, la estructura del trabajo está basada en un sistema de series que recogen centenares de fotografías. Como en L'art dans le Vieux Paris, donde realiza el registro de un París llamado a desaparecer en el contexto de finales del s. XIX.

Como hemos mencionado, el trabajo de Adget influiría notablemente en la Nueva Objetividad, marcando el devenir de la generación de fotógrafos y teóricos de la República de Weimar entre 1919 y 1933. De esta generación, bajo los planteamientos de la Neue Sachlichkeit se desarrollarán trabajos en diversas disciplinas artísticas, pero destacamos la generación de fotógrafos que compartirán una manera de entender la realidad social y política, así como los aspectos de la cotidianidad, "entendiendo la fotografía como un icono de la sociedad moderna" (Guasch, 2011, p. 30).

En la configuración de los planteamientos que extienden su sombra hasta los rastreadores de desechos, encontramos el hito que supuso la exposición Film und Foto Internationale Ausstellung (FIFO), en 1920, organizada por el miembro de la Bauhaus László Moholy Nagy. En ella se dieron cita artistas como Eugène Adget, Albert Renger-Patzsch, Karl Blossfeldt, John Heartfield, Hanna Höch o Helmar Lerski. La muestra supuso la consolidación de un concepto del trabajo fotográfico que permitió evolucionar el fotomontaje a una metodología de archivo enraizada en el siglo XIX, "que ponía su énfasis en el origen topológico, lineal y, en ocasiones, jerarquizado de los hechos" (Guasch, 2011, p. 31).

Un ejemplo paradigmático en esta línea sería la serie Ciudadanos del siglo $X X$, en la que el fotógrafo August Sander, miembro de la Nueva Objetividad, realiza una descripción de la sociedad de su tiempo mediante el retrato de personajes pertenecientes a diferentes categorías sociales y profesionales. El archivo, compuesto por un total de unas 540 imágenes, se encuentra distribuido en 45 carpetas compuestas por unas 12 fotografías clasificadas en siete volúmenes temáticos. Un catálogo fotográfico próximo al modelo de archivo, donde es fundamental la idea de "renovación", en este caso la renovación constante de la especie humana, lo que imprime un carácter circular a su obra (Guasch, 2011, p. 31).

Por tanto, el archivo fotográfico como concepto se enmarcaría en la tradición iniciada en la segunda mitad del siglo XX, cuando la fotografía evoluciona convirtiéndose en una herramienta para la comprensión de los procesos históricos mediante los recursos didácticos y mnemotécnicos (Foucault, 1970). Se trataría de propuestas que, mediante enunciaciones simples del pasado, tratan de volverlo al presente de manera no traumática; reforzadas por el contexto de contaminación visual actual, posibilitado por la implementación de la captura de imágenes en los dispositivos móviles y favorecido por la distribución global desde aplicaciones en red. 
Las expresiones artísticas analizadas en nuestro estudio, lejos de ceñirse al ámbito de los espacios físicos dedicados tradicionalmente al arte, encuentran en las redes sociales no solo un modo de compartir sus trabajos, sino que transforman el medio en mensaje. Ya que la propia organización del interfaz de las aplicaciones para compartir imágenes permite el uso, a la sombra del archivo, de la agrupación de las fotografías por álbumes de comunes o bajo un patrón de retícula. Junto al uso del hastag, o el tag, estas prácticas comprenderían algunas de las claves del archivo planteadas por Jaques Derrida (1997) entre las que añadiríamos el unificar, clasificar e identificar en un orden metodológico predeterminado.

De tal modo, encontramos agrupadas y clasificadas -en series fotográficas digitales, distribuidas en cuentas de redes sociales- imágenes del objeto desechado bajo la premisa de "acumular y clasificar una parte de la memoria colectica a partir del concepto de repetición propio del archivo hipomnémico" (Guasch, 2011, p. 52).

Dentro de esta categoría, encontramos una gran variedad de cuentas en redes sociales que comparten una serie de claves comunes. Destacando, dentro de su formalidad, que se trata de registros y encuadres descriptivos - con poca o ninguna intervención por parte del autorplenamente objetivos.

En base a esta característica, y con la intención de analizar los antecesores de los trabajos de los rastreadores, podemos observar claras relaciones con la citada Nueva Objetividad. Una tendencia que sería recuperada a finales de los años sesenta en relación con un renovado interés por el archivo, donde destacarían los fotógrafos Bern and Hilla Becher, llevando las claves surgidas a partir de la citada Film und Foto Internationale Ausstellung al límite mediante una radical objetividad, haciendo de su obra el trabajo archivístico que documentara un momento histórico vinculado al pasado industrial.

En este resurgir, destacaría la singularidad del referente y el trabajo mediante series agrupadas según tipologías. Es por tanto en estos trabajos, donde además de establecer una clara vinculación con el trabajo de la Nueva Objetividad, encontramos una estrecha relación con los archivos digitales de los rastreadores. Por tanto, el estilo documental de Bern and Hilla Becher aportaría las pautas que vemos reflejadas en nuestro objeto de estudio, marcadas por la exclusión de la subjetividad del autor mediante un enfoque frontal que pretende la exaltación de la mirada objetiva, sin contaminación o intervención manual o de postproducción digital. Estableciendo en este caso una nueva relación con el citado autor Walter Benjamin (2004) y su teoría del "inconsciente óptico" expuesta en su obra Pequeña historia de la fotografía (p. 28).

Del mismo modo, también encontraríamos una vinculación con otro de los grandes referentes del archivo, Christian Boltanski. Concretamente, con obras como L'inventaire des objets ayant appartenu à un resident de Oxford (1973) (Figura. 3) o L'inventaire des objets ayant appartenu à une femme de Bois-Colombes (1974). En estos trabajos Boltanski registra pertenencias personales y elementos cotidianos, haciendo de ellos símbolos de la memoria. 


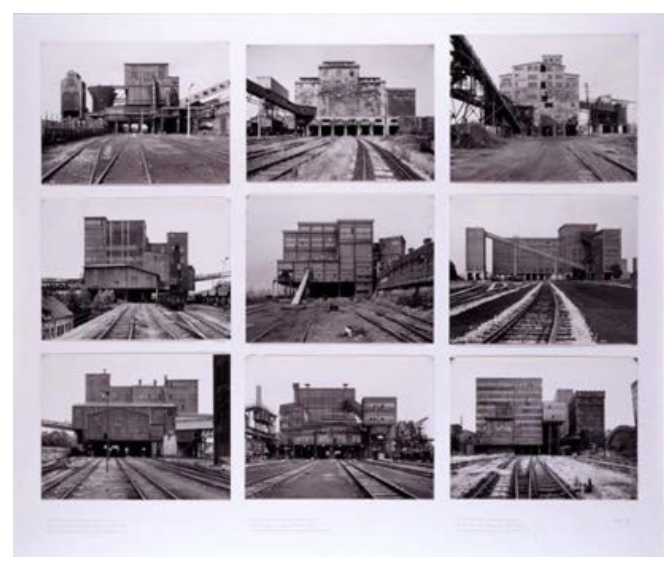

Figura 1. Aufbereitungsanlagen (Plantas de preparación). (1966-1976). Bernd Becher and Hilla Becher. Gelatinobromuro de plata sobre papel. Fuente: https://www.museoreinasofia.es/coleccion/obra/ aufbereitungsanlagen-plantas-preparacion

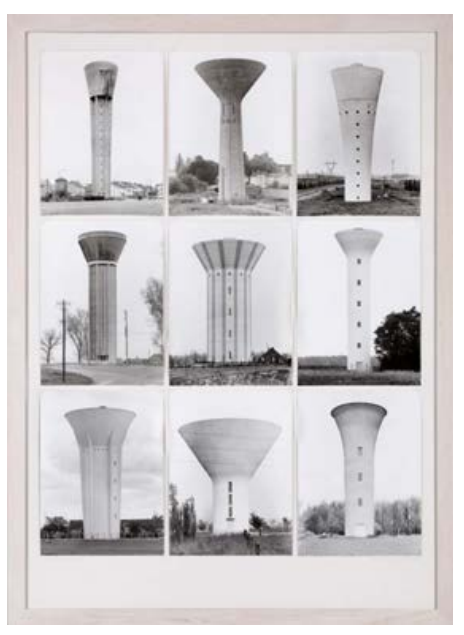

Figura 2. Typology of Watertowers (Tipología de torres de agua). (1972). Bernd Becher and Hilla Becher. Gelatinobromuro de plata sobre papel. Fuente: https://www.museoreinasofia. es/coleccion/obra/typology-

watertowers-tipologia-torres-agua

En esta línea cabe destacar, como representativa del trabajo que explora las nociones de archivo y memoria en Boltanski, la obra presentada en la Documenta 8 de Kassel en 1987, que llevaría por título Les archives donde presenta una serie de 366 fotografías de retratos y escenas domésticas. Esta agrupación se encuentra relacionada con las imágenes exhibidas en los campos de concentración nazis y los archivos de la policía francesa de la ocupación alemana.

El hecho de destacar estos trabajos de Boltanski responde al interés por una estética del archivo, claramente relacionada con la idea de memoria. Prestando atención a su relación con las prácticas de los rastreadores, son obras que no pretenderían la reestructuración del pasado, si no "la recuperación y la constatación de la memoria como un hecho cultural, antropológico y existencial" (Guasch, 2011, p. 58). Esta memoria, tanto para Boltanski como para los rastreadores, se muestra a través de los fósiles que pertenecen al pasado, objetos encontrados del espectro de lo cotidiano.

De tal manera observamos como los rastreadores mediante sus registros fotográficos, y Boltanski en sus trabajos de archivos, aíslan a un objeto de su contexto original o registran un objeto descontextualizado. Este hecho permite elevarlos a la obra de museo en Boltanski, o al archivo de las redes sociales en los rastreadores. De tal forma que "les procura un aura que transforma esos objetos en reliquias modernas que aluden a lo perdido" (Guasch, 2011, p. 60). 


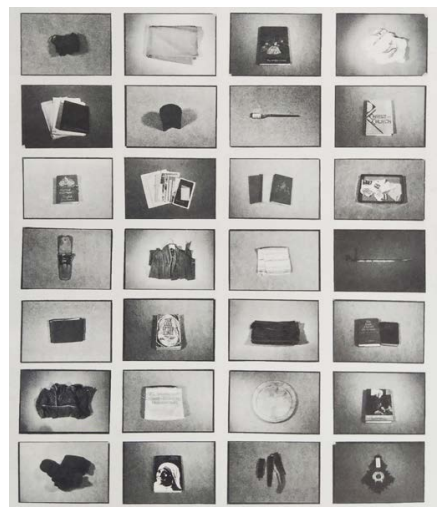

Figura 3. L'inventaire des ibjetts ayant appartenu à un resident de Oxford. (1973). Christian Boltanski. Fuente: Guasch, A. M. (2011). Arte y Archivo, 1920-2010 Genealogías, tipologías y discontinuidades. Madrid: AKAL

Por otra parte, entre los artistas que guardarían una relación directa como antecesores del trabajo de los rastreadores, quisiéramos prestar atención a la obra de Edward Ruscha, y especialmente a las publicaciones de sus fotolibros. Nos apoyaremos como ejemplo en su primer trabajo realizado en esta línea, Twentysix Gasoline Stations (1963) (Figura. 4), donde se recoge una muestra de gasolineras que se encuentran en el recorrido de la ruta 66 Oeste-Este, desde California hasta Texas. Nos interesa destacar la organización fotográfica a través de nociones como la secuencialidad, la seriación y la repetición en este trabajo. Unas características que podemos encontrar en el orden de las fotografías que los rastreadores comparten en sus muros de las redes sociales. De igual manera, podemos destacar la ausencia de la figura humana, o insignificante presencia, en ambas colecciones de registros, y como se presta especial atención a la inexpresividad y la objetividad con la que se presentan las imágenes.

Con ello, podemos observar una clara relación en la voluntad de documentar lo factual de una manera lacónica, alejado de las convenciones de la fotografía artística o de moda. Un contexto que Edward Ruscha cuestionaría con sus fotolibros, y en el caso que nos ocupa, la vanidad que inunda actualmente las redes sociales.

Por otra parte, una vez revisados brevemente los antecedentes y señaladas las claves que compartirían con los rastreadores, resulta relevante señalar que en este caso nos enfrentaríamos a un fenómeno claramente global. Se trataría de una corriente activista no organizada donde los usuarios (muchos de ellos incluirían algún dato en referencia a la localización geográfica en el identificador de su cuenta) se encuentran diseminados en lugares distantes del planeta y, quizás el dato más relevante, sin aparente conexión entre los diferentes miembros. Por último, cabría señalar la evidente búsqueda del anonimato de sus autores, ya que las cuentas desde donde se difunden estas imágenes se identifican a través de un alías o nick en forma de alter ego, una práctica que podríamos considerar próxima a las acciones del street art. 


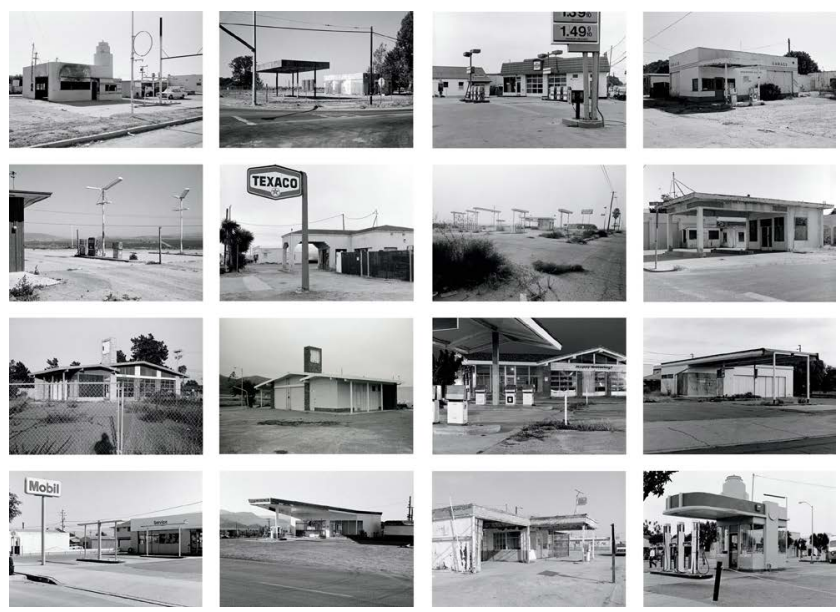

Figura 4. Twentysix Gasoline Stations (1962). Edward Ruscha. Fuente: https://www.nytimes.com/2013/06/02/books/review/varioussmall-books-inspired-by-ed-ruscha-and-more.html

A continuación, y a modo de ilustración de nuestras reflexiones, abordaremos una serie de cuentas objeto de nuestro estudio que trabajan en el marco de Instagram, una aplicación y red social de origen estadounidense fundada en 2010, y que dos años más tarde fue adquirida por Facebook. Según datos de DataReportal, en enero de 2020 era la sexta red social más utilizada a nivel mundial, con alrededor de 1.000 millones de usuarios activos mensuales ${ }^{1}$, y la más popular en el ámbito de las aplicaciones de compartición de imágenes.

El muestreo que presentamos lo dividiremos en tres grandes apartados, atendiendo a las tipologías de los objetos registrados y la autoría de las imágenes.

En primer lugar, las cuentas colaborativas especializadas en todo tipo de asientos. En este caso, la individualidad y la autoría pasan a un segundo plano, frente al objeto y la temática del archivo. La que ofrece una colección más extensa sería @couchesofportland (Figura. 5), con 608 registros de sofás abandonados en la ciudad de Porland en Oregón. Se trata de una cuenta que pone a disposición de sus usuarios un e-mail, para qué puedan enviar aquellos registros, convirtiéndose al usuario en miembro de la comunidad de rastreadores. Del mismo modo que las cuenta @societyoflonely con 399 registros de muebles de asiento abandonados, @ freecochesofeastvan con 346 registros de mobiliarios de asiento, y @couchesofnewyork con 94 registros de muebles de asiento en la ciudad de New York. Esta tipología de cuenta colaborativa da muestra de uno de los factores que vinculan a los rastreadores del desecho con la fotografía documental, al tratarse de capturas no meditadas, totalmente objetivas y no posproducidas.

Por otra parte, encontraríamos cuentas interesadas en la obsolescencia de los objetos tecnológicos, prestando especial interés por los electrodomésticos e introduciendo en su nick el objeto del archivo. De entre ellas, destacaremos @tvsonthesideogtheroad (Figura. 6), con 784 registros de televisores abandonados, y @fridges_of_slough_county con 267 registros de frigoríficos abandonados en la ciudad de Slough en Reino Unido. En estos ejemplos, la muestra del desecho dejado por la ruina del progreso se muestra de manera más áspera. En muchos de 
los casos, nos encontramos ante objetos completamente destrozados, al tiempo que acrecientan su estatus de escombro abandonado por el deseo de renovación del consumismo exacerbado. Al registrar objetos electrónicos, hijos del avance tecnológico y abandonados testigos de la desmantelada idea de progreso ascendente, expresan una visión que evidenciaría la anulación de la posibilidad de una mirada nostálgica, haciéndose patente la función arqueológica como simulacro.

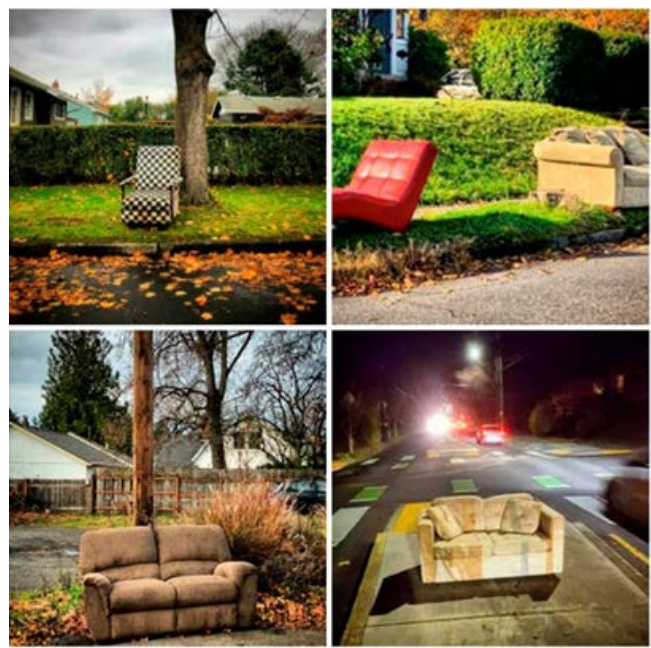

Figura 5. @couchesofportland. (2019). INSTAGRAM. Fuente: https://www.instagram.com/ couchesofportland/?hl=es
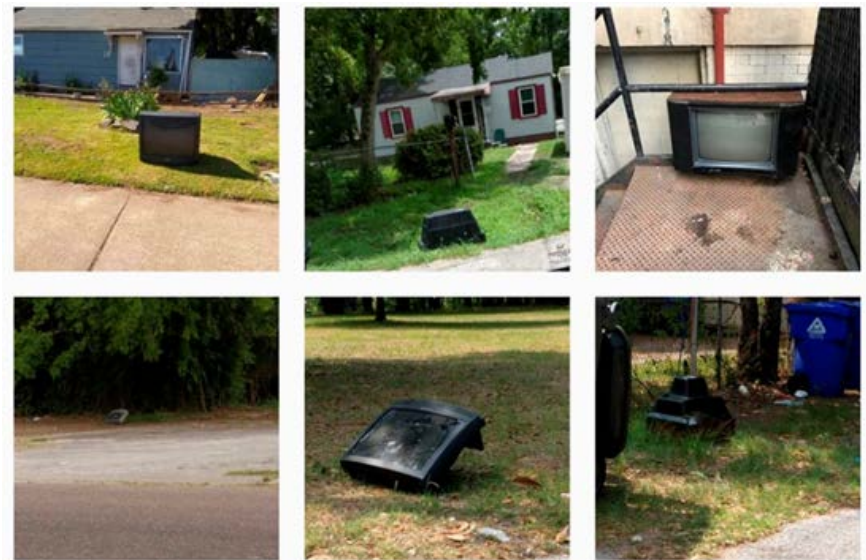

Figura 6. @tvsonthesideoftheroad. (2019). INSTAGRAM. Fuente: https://www.instagram.com/tvsonthesideoftheroad/?hl=es 
Para concluir nuestra exposición, compartiremos cuentas interesadas en enseres en general, y mobiliario doméstico en especial. La que presenta una menor especialización sería @ matresses_of_berlin, con 273 publicaciones de todo tipo de enseres personales abandonados en la ciudad alemana, principalmente colchones y mobiliario de asiento. En Filadelfia Sur se localiza @the_street_furniture_of_sp,con 525 registros de mobiliario desechado. La berlinesa @abandonedsofasberlin, con 105 registros de muebles de asiento. Con 83 registros de mobiliario de asiento principalmente, @notesientesbasura, sin concretar su localización geográfica. El mobiliario de asiento abandonado es la especialidad de @couchesofdelco (Figura. 7), con 41 registros. $Y$, con la peculiaridad de intercalar el archivo de registros con las publicaciones de interpretaciones artísticas del objeto y fotografías de archivos del mismo, @uglycouchqueen, con 186 entradas de muebles de asiento. En estas cuentas se muestra, de manera más evidente que en los casos anteriores, una vinculación con el referente al tratarse de elementos que se encuentran asociados a nuestra cotidianidad. Almacenamos en nuestra memoria recuerdos en los cuales los enseres han formado parte de nuestra vida, y el hecho de identificar elementos cargados de significado fuera de su contexto, rescatados de entre las ruinas, es un factor esencial para generar metafóricamente la vuelta al tiempo presente de un pasado reciente, obligándonos a hacer un ejercicio tanto de recuperación como de reinterpretación de este.
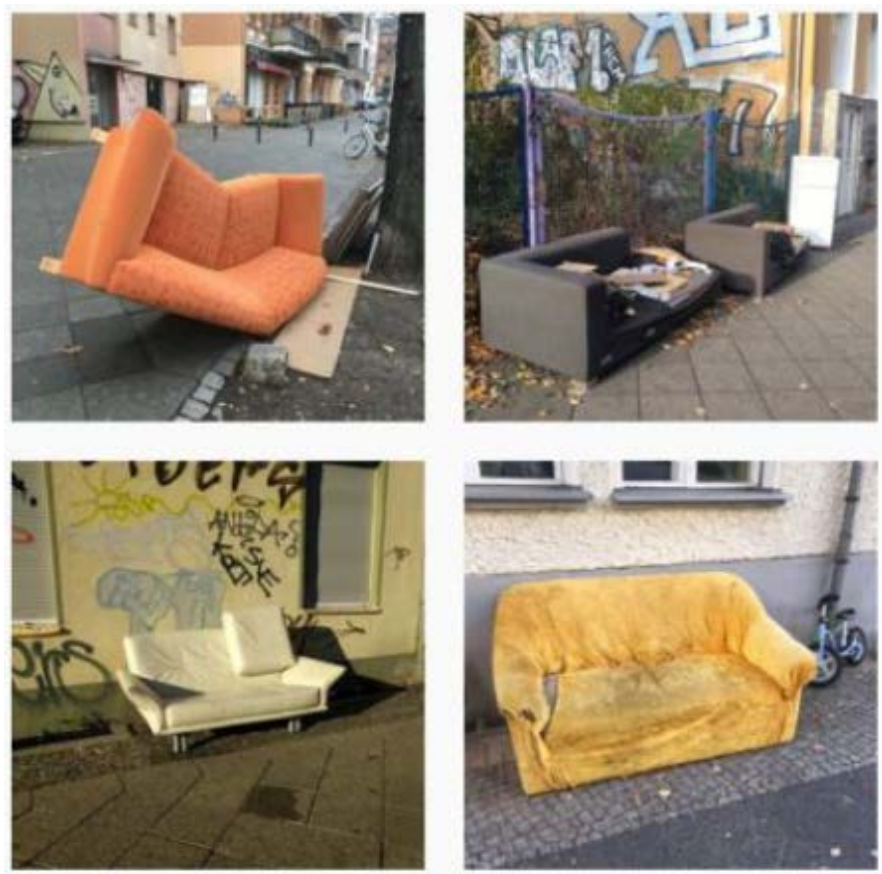

Figura 7. @ couchesofdelco. (2019). INSTAGRAM. Fuente: https://www.instagram.com/couchesofdelco/?hl=es 
Francisco de la Torre Oliver ha sido el encargado de abordar el $40 \%$ del trabajo, aportando de esta forma su investigación en el apartado 3 "Fotografía digital y claves del cambio de paradigma". Y, por otra parte, Eduardo Serrano González ha desarrollado el $60 \%$ del total, exponiendo sus investigaciones teóricas en el apartado 2 "La memoria y el escombro". En cuanto al apartado 4 "Discursos de los rastreadores de desechos en las redes sociales", las conclusiones y planteamiento de la tesis han sido un trabajo conjunto de los dos autores.

\section{CONCLUSIONES}

Una vez realizado el desarrollo, en base a nuestros objetivos, podemos responder a nuestra hipótesis de manera positiva al haber encontrado claves conceptuales comunes en los rastreadores. Existiría una unidad en base a la mirada de la historia, el objeto y la memoria. Así como, una vinculación con la tradición fotográfica de archivo de los referentes analizados, lo cual nos ha permitido otorgarles una capacidad de unidad y grupo propio en base a la nomenclatura de Rastreadores de Desechos.

De este modo, hemos analizado como este grupo de fotógrafos aplicarían, en cierto sentido, la mirada del Ángel de la Historia de Walter Benjamin, para revisar el pasado a través de su objetivo, registrando aquellos desechos encontrados entre las ruinas de la sociedad. Una forma de mirar que les dota de unidad y les enmarca dentro de la tradición de pensamiento en la forma de interpretar el pasado.

De igual manera, hemos podido analizar y desarrollar las claves conceptuales de un fenómeno como el desecho. De esta forma, se ha observado que el objeto abandonado es utilizado por nuestros autores como metáfora del pasado reciente. Por lo tanto, los registradores exploran la capacidad de generar discursos a través de su registro, investigando al tiempo la capacidad que otorga la descontextualización del objeto cotidiano. Este hecho permite a los rastreadores evocar, mediante sus fotografías, no solo la memoria colectiva sino también la individual. Ya que, derivada de nuestra experiencia vital con los objetos cotidianos, asociamos momentos y recuerdos almacenados en nuestra memoria que volverían al presente mediante la evocación del objeto desechado.

Por lo tanto, tras nuestro análisis entendemos que los rastreadores escarban en las ruinas del progreso, registrando con sus cámaras de entre los escombros objetos desechados, de tal forma que serían transferidos al presente. Pero como hemos podido analizar, este retorno no se ejecutaría desde una voluntad de recuerdo melancólico, por el contrario, se trataría de aludir a un sentir colectivo, de tal manera que esta evocación permita realizar nuevas interpretaciones de nuestro pasado.

Comprender las claves conceptuales que nos permiten trazar un interés común entre los rastreadores nos ha posibilitado enmarcarlos en una tradición fotográfica concreta. Pese al cambio de paradigma de lo fotografiable, al incorporarse la cámara en los dispositivos móviles y el giro hacia la banalidad y la sobreabundancia que han favorecido las aplicaciones de compartición de fotografías, existe una vinculación en los registradores con la tradición de archivo iniciada a finales del siglo XIX. El análisis de esta vinculación con los referentes artísticos, junto a los conceptuales, nos ha ayudado a refutar nuestra hipótesis de que los rastreadores de desechos pueden configurarse como una corriente propia, al responder a una tradición. 
Por ello, tras exponer nuestra investigación, podríamos confirmar la existencia de una corriente de registro fotográfico, que utiliza las redes sociales, subvirtiendo su orden inicial, para desarrollar discursos artísticos. Este fenómeno, además, se enmarcaría en unas líneas de pensamiento común vinculadas a una tradición fotográfica de archivo. Todo ello, permite que nos encontremos frente a una tendencia fotográfica, con un discurso propio sólido y crítico, con capacidad de cuestionar nuestro pasado reciente y construir ideas de futuro a partir del registro de los objetos desechados.

\section{REFERENCIAS}

Barthes, R. (1986). Lo obvio y lo obtuso. Barcelona: Paidós.

Baudrillard, J. (1969). El sistema de los objetos. México D.F: Siglo XXI.

Bauman, Z. (2018). Retrotopía. Barcelona: Paidós.

Benjamin, W. (2004). Sobre la fotografía. Valencia: Pre-Textos.

Benjamin, W. (2005). Tesis sobre la historia y otros fragmentos. México D.F: Ítaca.

Bollas, C. (1987). La sombra del objeto. Psicoanálisis de lo sabido no pensado. Buenos Aires: Amorrortu.

Boym, S. (2001). The Future of Nostalgia. Nueva York: Basic Books.

Derrida, J. (1997). Mal de archive: una impresión freudiana. Madrid: Trotta.

Enwezor, O. (2008). Archive forever: uses of the Document in Contemporary Art. New York: Steidl.

Fernández, A. (2018). Teoría general de la basura (cultura, apropiación, complejidad). Barcelona: Galaxia Gutenberg.

Foucault, M. (1970). La arqueología del saber. México D.F: Siglo XXI.

Guasch, A. M. (2011). Arte y Archivo, 1920-2010 Genalogías, tipologías y discontinuidades. Madrid: Akal.

Guigon, E. (1997). El objeto surrealista. Valencia: IVAM.

Hernández, M. Á. (2012). Materializar el pasado: el artista como 
historiador (Benjaminiano). Murcia: Micromegas.

Krauss, R. (2002). Los espacios discursivos de la fotografía. En Lo fotográfico por una teoría de los desplazamientos (pp. 40-59). Barcelona: Editorial Gustavo Gili, S.A.

Martín Prada, J. (2018). El ver y las imágenes en el tiempo de internet. España: Akal.

Reyes, A. (1989). La Malicia del Mueble, Obras completas XXII. México: FCE.

Sontag, S. (2005). Sobre la fotografía. Madrid: Alfaguara.

\section{NOTAS}

1. https://es.statista.com/estadisticas/600712/rankingmundial-de-redes-sociales-por-numero-de-usuarios/ 